\title{
Hubungan Asupan Makanan dan Obesitas dengan Kejadian Arthritis Reumatoid pada Lansia di Panti Sosial Tresna Werdha Inakaka Ambon
}

\author{
Zasendy Rehena' ${ }^{1}$, Frans Romroma ${ }^{2}$, dan Lydia M Ivakdalam ${ }^{3 凶}$ \\ ${ }^{1,3}$ Staf Pengajar Program Studi Kesehatan Masyarakat Universitas Kristen Indonesia Maluku. Ambon. Indonesia, \\ Email : rehenasasendi@gmail.com, ivakdlmlydia@gmail.com \\ 2 Staf Pengajar Program Studi Keperawatan Universitas Kristen Indonesia Maluku. Ambon. Indonesia, \\ Email : mymorph91@gmail.com \\ ${ }_{\text {Korespondensi : Lydia M Ivakdalam, Universitas Kristen Indonesia Maluku, Ambon, Indonesia, }}$ \\ Email : ivakdlmlydia@gmail.com
}

\begin{abstract}
ABSTRAK.
Meningkatnya populasi lanjut usia ini menyebabkan perlunya antisipasi meningkatnya jumlah pasien lanjut usia yang memerlukan bantuan untuk mengatasi masalah kesehatan pada lansia terutama masalah arthritis reumatoid. Artritis reumatoid merupakan penyakit autoimun yang ditandai oleh inflamasi kronik dan progresif dengan sendi merupakan sasaran utama. berdasarkan informasi dari petugas kesehatan dipanti Sosial Tresna Werdha Inakaka Ambon penyakit arthritis reumatoid atau rematik masuk dalam 3 besar penyakit yang paling sering di alami oleh lansia. Tujuan; penelitian ini untuk mengetahui hubungan asupan makanan dan obesitas dengan penyakit Arthritis Reumatoid Di Panti Sosial Tersna Werdha Inakaka Ambon. Metode Penelitian ini menggunakan penelitian deskriptif dengan menggunakan rancangan cross sectional. Pengambilan sampel dengan metode total sampling. data dianalisis dengan mengunakan Uji chi square test. Hasil penelitian menunjukan ada hubungan Asupan makanan dengan arthritis reumatoid, nilai $\rho=0,000$ dan ada hubungan antara obesitas dengan arthritis reumatoid, nilai $\rho=0,003$, dan. Kesimpulan bahwa asupan makanan dan obesitas berhubungan dengan arthritis reumatoid. Diharapkan hasil penelitian ini dapat menjadi bahan pertimbangan dalam upaya meningkatkan mutu pelayanan untuk meningkatkan kualitas hidup dan kesehatan lansia dipanti sosial tresna werdha inakaka ambon.
\end{abstract}

\section{Keywords: Asupan makanan, Obesitas, Arthritis Reumatoid}

\section{PENDAHULUAN}

Menjadi tua adalah suatu keadaan yang terjadi di dalam kehidupan manusia. Menua merupakan proses sepanjang hidup, tidak hanya dimulai dari satu waktu tertentu, tetapi dimulai sejak waktu permulaan kehidupan. Memasuki usia tua berarti mengalami kemunduran misalnya kemunduran fisik yang ditandai dengan kulit yang mengendur, rambut memutih, gigi mulai ompong, pendengaran kurang jelas, penglihatan semakin memburuk, gerakan lambat, figur tubuh yang tidak proporsional (Ahdaniar, 2014).

Saat ini, jumlah lansia di dunia diperkirakan lebih dari 629 juta jiwa (Depkes RI, 2013). Hasil sensus penduduk Tahun 2013 menunjukkan bahwa Indonesia termasuk lima besar negara dengan jumlah penduduk lansia terbanyak di dunia yakni mencapai 18,1 juta jiwa atau 9,6 \% dari jumlah penduduk populasi lanjut usia di Indonesia diproyeksikan antara tahun 1990-2023 akan naik 4,14\%, suatu angka tertinggi di seluruh dunia dan pada tahun 2020 Indonesia merupakan urutan ke-4 jumlah usia lanjut paling banyak sesudah China, India dan Amerika Serikat. Meningkatnya populasi lanjut usia ini menyebabkan perlunya antisipasi meningkatnya jumlah pasien lanjut usia yang memerlukan bantuan untuk mengatasi masalah kesehatan pada lansia, salah satunya adalah masalah Artritis reumatoid (Susanto, 2013).

Artritis reumatoid adalah penyakit autoimun yang ditandai oleh inflamasi sitemik kronik dan progresif dengan sendi merupakan sasaran utama. Gejala artritis reumatoid adalah poliartritis simetris terutama pada sendi sendi kecil tangan dan kaki. Masalah yang disebabkan oleh penyakit arthritis reumatoid tidak hanya berupa keterbatasan yang tampak jelas pada mobilitas dan aktivitas 
hidup sehari-hari tetapi juga efek sistemik yang tidak jelas yang dapat menimbulkan kegagalan organ. Penyebab dari arthritis reumatoid diantaranya obesitas dan asupan makanan yang menjadi faktor pemicu artritis pada lansia (Ahdaniar 2014).

Arthritis reumatoid akan beresiko lebih tinggi bila terjadi obesitas akibat dari penimbunan lemak tubuh yang berlebihan. Sebagian besar penderita arthritis reumatoid selalu mengalami obesitas karena keadaan ini dapat meningkatkan tekanan pada tulang sehingga tulang rawan yang terdapat di persendian bisa semakin cepat aus (Aru, 2007). Mengkonsumsi makanan yang mengandung purin dapat meningkatkan kadar asam urat yang menyebabkan terjadinya pengkristalisasian dalam sendi. Agar terhindar dari penyakit arthritis reumatoid akut salah satunya menjaga kadar asam urat dalam darah di posisi normal, yaitu 5-7 mg\% (Supariasa, 2012).

Pengambilan data awal pada bulan Mei 2017, jumlah lansia 25 orang laki-laki dan 43 orang perempuan dan dari informasi yang diperoleh menunjukkan bahwa sebagian besar lansia menderita nyeri sendi. Hal ini dibuktikan dengan data dari Panti Sosial Tresna Werdha Inakaka Ambon pada tahun 2015 yang menderita rematik 20 orang dari 74 lansia. Dan pada tahun 2016 mencapai 24 orang dari 72 orang serta pada tahun 2017 bulan Mei lansia yang terdiagnosa arthritis reumatoid sebanyak 10 orang. berdasarkan hasil wawancara dan informasi dari petugas kesehatan dipanti Sosial Tresna Werdha Inakaka Ambon penyakit arthritis reumatoid atau rematik masuk dalam 3 besar penyakit yang paling sering di alami oleh lansia.

Berdasarkan uraian tersebut, maka penelitian ini bertujuan untuk mengetahui hubungan asupan makanan dan obesitas dengan penyakit Arthritis Reumatoid Di Panti Sosial Tersna Werdha Inakaka Ambon

\section{METODE PENELITIAN}

Penelitian ini adalah penelitian deskriptif analitik dengan menggunakan pendekatan Cross Sectional dan dilaksanakan pada bulan Agustus sampai September 2017 di Panti Sosial Tresna Werdha Inakaka Ambon. Pengambilan sampel dengan metode total sampling. Sampel dalam penelitian ini adalah Semua lansia yang berada Di Panti Sosial Tresna Werdha Inakaka Ambon yang berjumlah 66 orang. Variabel dalam penelitian ini adalah variabel bebas yaitu asupan makanan dan obesitas, variabel terikat yaitu Artritis rheumatoid. Instrumen yang digunakan dalam penelitian ini adalah kuesioner yang berisi pertanyaan terkait dengan Artritis rheumatoid. Variabel Asupan makanan diukur menggunakan metode food frequency dan variabel Obesitas menggunakan alat ukur Timbangan untuk mengukur Berat Badan dan mikrotoa untuk mengukur tinggi badan. Semua data dianalisis menggunakan uji chi-square.

\section{HASIL DAN PEMBAHASAN}

\subsection{Karakteristik responden}

Analisis univariat dilakukan untuk karakteristik responden berdasarkan umur, jenis kelamin, adalah sebagaimana yang digambarkan pada Tabel 1 berikut ini.

\begin{tabular}{lcc}
$\begin{array}{l}\text { Tabel 1. Karakteristik responden di } \\
\text { Werdha Inakaka Ambon }\end{array}$ & Sosial & Tresna \\
\hline \multicolumn{1}{c}{ Karakteristik Responden } & n & \% \\
\hline Umur & & \\
60-74 tahun & 31 & 47,0 \\
$75-90$ tahun & 34 & 51,5 \\
$\quad \quad 90$ tahun & 1 & 1,5 \\
Jenis Kelamin & & \\
$\quad$ Laki -laki & 26 & 39,4 \\
$\quad$ Perempun & 40 & 60,6 \\
Asupan Makanan & & \\
$\quad$ Kurang & 16 & 24,2 \\
$\quad$ Baik & 50 & 75,8 \\
$\quad$ Obesitas & & \\
$\quad$ Tidak Obesitas & 13 & 19,7 \\
Arthritis Reumatoid & 53 & 80,3 \\
$\quad$ Arthritis Reumatoid & & \\
& 40 & 60,6
\end{tabular}


Tidak

26

39,4

Hasil analisis univariat terhadap karakteristik responden yang terlihat pada Tabel 1 menunjukan bahwa responden yang terbanyak adalah pada kelompok umur 75-90 tahun yakni berjumlah 34 orang (51,5\%), sedangkan berdasarkan jenis kelamin, perempuan lebih banyak dibandingkan laki-laki yakni sebanyak 40 orang $(60,6 \%)$. Dari Tabel 1 juga terlihat bahwa responden yang mengalami obesitas berjumlah 13 orang $(19,7 \%)$ dan tidak obesitas berjumlah 53 orang (80,3\%). Respnden yang memiliki Asupan makanan baik berjumlah 50 orang $(75,8 \%)$ dan kurang baik berjumlah 16 orang (24,2\%). Responden yang menderita Arthritis Reumatoid lebih banyak dibandingkan dengan responden yang tidak menderita Arthritis Reumatoid yakni berjumlah 40 orang $(60,6 \%)$.

\subsection{Analisis Bivariat}

Hubungan Asupan Makanan dengan Kejadian arthritis reumatoid pada lansia di Panti Sosial Tresna Werdha Inakaka Ambon dapat dilihat pada Tabel 2.

Tabel 2. Hubungan Asupan Makanan dengan Arthritis Reumatoid pada Lansia

\begin{tabular}{|c|c|c|c|c|c|c|c|}
\hline \multirow{3}{*}{ Asupan makanan } & \multicolumn{4}{|c|}{ Arthritis Reumatoid } & \multirow{2}{*}{\multicolumn{2}{|c|}{ Total }} & \multirow{3}{*}{$\boldsymbol{P}$} \\
\hline & \multicolumn{2}{|c|}{$\begin{array}{c}\text { Arthritis } \\
\text { Reumatoid }\end{array}$} & \multicolumn{2}{|c|}{ Tidak } & & & \\
\hline & $\mathbf{n}$ & $\%$ & $\mathbf{n}$ & $\%$ & $\mathbf{n}$ & $\%$ & \\
\hline kurang & 15 & 22,7 & 1 & 1,5 & 16 & 24,2 & \\
\hline Baik & 25 & 37,9 & 25 & 37,9 & 50 & 75,8 & 0,000 \\
\hline Total & 40 & 60,6 & 26 & 39,4 & 66 & 100 & \\
\hline
\end{tabular}

Hasil pada Tabel 2 menunjukkan bahwa dari 66 responden yang diteliti, responden dengan asupan makanan yang kurang dan menderita arthritis reumatoid sebanyak 15 orang $(22,7 \%)$ dan responden dengan asupan makanan yang baik dan menderita arthritis reumatoid berjumlah 25 orang (37,9\%). Responden dengan asupan makanan yang kurang dan tidak menderita arthritis reumatoid hanya 1 orang $(1,5 \%)$ dan Responden dengan asupan makanan yang baik dan tidak menderita arthritis reumatoid berjumlah 25 orang $(37,9 \%)$.

Hasil uji statistik dengan menggunakan uji chi scuare untuk melihat hubungan antara asupan makanan dan arthritis reumatoid didapatkan bahwa nilai $\mathrm{p}=0,000(\mathrm{p}<0,05)$, yang artinya H0 ditolak dan Ha diterima. Maka disimpulkan bahwa ada hubungan antara asupan makanan dengan kejadian arthritis reumatoid pada lansia di panti Sosial Tresna Werdha Inakaka Ambon.

Hubungan Obesitas dengan Kejadian arthritis reumatoid pada lansia di Panti Sosial Tresna Werdha Inakaka Ambon dapat dilihat pada Tabel 3.

Tabel 3. Hubungan Obesitas dengan Kejadian Arthritis Reumatoid pada Lansia

\begin{tabular}{|c|c|c|c|c|c|c|c|}
\hline \multirow{3}{*}{ Obesitas } & \multicolumn{4}{|c|}{ Arthritis Reumatoid } & \multirow{2}{*}{\multicolumn{2}{|c|}{ Total }} & \multirow{3}{*}{$p$} \\
\hline & \multicolumn{2}{|c|}{$\begin{array}{c}\text { Arthritis } \\
\text { Reumatoid }\end{array}$} & \multicolumn{2}{|c|}{ Tidak } & & & \\
\hline & $\mathbf{n}$ & $\%$ & $\mathbf{n}$ & $\%$ & $\mathbf{n}$ & $\%$ & \\
\hline Obesitas & 13 & 19,7 & 0 & 0 & 13 & 19,7 & \\
\hline Tidak & 27 & 40,9 & 26 & 39,4 & 53 & 80,3 & 0,003 \\
\hline Total & 40 & 60,6 & 26 & 39,4 & 66 & 100 & \\
\hline
\end{tabular}

Tabel 3 menunjukkan bahwa dari 66 responden yang diteliti, responden yang obesitas dan mengalami arthritis reumatoid berjumlah 13 orang $(19,7 \%)$ dan responden yang tidak obesitas tetapi mengalami arthritis reumatoid berjumlah 27 orang $(40,9 \%)$. Responden yang obesitas dan tidak mengalami arthritis reumatoid tidak ada $(0 \%)$ dan responden yang tidak obesitas dan tidak mengalami arthritis reumatoid berjumlah 26 orang (39,4\%). Hasil uji statistik dengan menggunakan uji chi scuare untuk melihat hubungan obesitas dengan arthritis reumatoid didapatkan bahwa nilai $\mathrm{p}=0,003(\mathrm{p}<0,05)$, yang artinya H0 ditolak dan Ha diterima. Maka disimpulkan bahwa ada hubungan antara obesitas dengan arthritis reumatoid pada lansia di panti Sosial Tresna Werdha Inakaka Ambon. 


\subsection{PEMBAHASAN}

\subsubsection{Hubungan Asupan Makanan dengan Kejadian arthritis reumatoid pada lansia di Panti Sosial Tresna Werdha Inakaka Ambon}

Hasil uji statistik dengan menggunakan uji chi scuare untuk melihat hubungan Asupan makanan dengan arthritis reumatoid pada tabel 2 didapatkan bahwa nilai $\mathrm{p}=0,000(\mathrm{p}<0,05)$, yang artinya H0 ditolak dan Ha diterima. Hal ini berarti ada hubungan antara asupan makanan dengan arthritis reumatoid pada lansia di panti Sosial Tresna Werdha Inakaka Ambon. Asupan makanan yang dimaksudkan dalam penelitian ini adalah jenis makanan yang mengandung zat purin dikonsumsi lansia seperti jeroan, sayuran hijau dan kacang-kacangan yang dikonsumsi oleh lansia. Hal ini disebabkan karena responden dengan asupan gizi yang kurang baik sering mengkonsumsi makanan diluar diet yang telah diberikan oleh panti. Responden membeli makanan atau jajanan dari luar atau yang dibawa langsung oleh keluarga dimana terdapat bahan makanan yang mengandung purin seperti sayur daun singkong, kangkung yang hampir setiap hari dikonsumsi oleh lanisa. kacang-kacangan, makanan bersantan dan sea food. dengan demikian dapat disimpulkan bahwa kebanyakan lansia sering mengkonsumsi makanan dengan kadar tinggi purin menderita rematik. Hasil yang peneliti temukan, petugas panti yang menyediakan dan menetapkan diet atau makanan untuk masing-masing lansia akan tetapi karena kemauan lansia sendirilah yang ingin mengkonsumsi makanan dari luar dengan alasan merasa bosan.

Supariasa, (2012) menyatakan bahwa asupan gizi sangat diperlukan bagi usia lanjut sehat untuk mempertahankan kualitas hidupnya. Sementara untuk usia lanjut yang sakit, asupan makanan diperlukan untuk proses penyembuhan dan mencegah agar tidak terjadi komplikasi lebih lanjut dari penyakit yang dideritanya. Mengkonsumsi makanan yang mengandung purin dapat meningkatkan kadar asam urat yang menyebabkan terjadinya pengkristalisasian dalam sendi. Agar terhindar dari penyakit rematik artritis akut salah satunya menjaga kadar asam urat dalam darah di posisi normal, yaitu 5-7 mg\%.

Dari hasil penelitian juga ditemukan fakta lain bahwa responden dengan asupan makanan yang baik dan menderita arthritis reumatoid sebanyak 25 orang (37,9\%). Hal ini menunjukan bahwa sebagian lansia mengikuti anjuran dan diet yang telah ditetapkan oleh panti umumnya makananmakanan dengan zat purin yang tinggi karena lansia rutin mengkonsumsi makanan yang disediakan langsung dari panti tetapi tidak menutup kemungkinan lansia tersebut terhindar dari penyakit Arthritis Reumatoid karena faktor lain yang mempengaruhi diantaranya olahraga dan riwayat trauma. Karena masa lanjut usia adalah masa dimana terjadi penurunan fungsi tubuh dan sendi yang menyebabkan lansia rentan terhadap penyakit (Bandiyah. S, 2009).

Penelitian ini sejalan dengan penelitian yang dilakukan oleh Ren, et al (2016), Jika pola makan benar, kesehatan terjaga, sebaliknya apabila pola makan tidak benar, besar kemungkinan kita akan terkena berbagai penyakit. zat-zat yang sangat membayakan tubuh berhubungan erat dengan gangguan metabolisme dimana zat purin yang memicu peningkatan kadar asam urat dalam darah (hiperurisemia) (Junaidi, 2012). Hubungan positif bermakna sering seseorang mengkonsumsi makanan yang mengandung tinggi purin semakin tinggi pula kadar asam urat dalam darah yang dapat berakibat kepenyakit arthritis reumatoid dan penyakit arthritis lainnya seperti asam urat.

Hasil penelitian Bawarodi, dkk (2017) juga menunjukan bahwa terdapat hubungan pola makan dengan kekambuhan rematik di Wilayah Puskesmas Beo Kabupaten Talaud. Dalam penelitian ini terdapat responden yang memiliki pola makan yang tidak tetapi tidak sering mengalami kekambuhan yaitu sebanyak 3 responden (33,3\%), begitupun sebaliknya ada juga responden yang memiliki polah makan baik tetapi sering mengalami kekambuahn yaitu sebanyak 23 responden sebanyak (79,3\%). Hal ini disebabkan karena adanya kebiasaan mengomsumsi makanan yaitu yang dapat memicu terjadinya kekambuhan rematik, karena makanan merupakan faktor penting dalam memicu kekambuhan penyakit rematik seperti, menghindari produk susu, buah jeruk, tomat, jeroan, dan makanan tertentu lainnya.

\subsubsection{Hubungan Obesitas dengan Kejadian arthritis reumatoid pada lansia di Panti Sosial Tresna Werdha Inakaka Ambon}

Hasil uji statistik dengan menggunakan uji chi scuare untuk melihat hubungan obesitas dengan arthritis reumatoid dalam tabel 3 menunjukkan bahwa nilai $p=0,003(p<0,05)$, yang artinya H0 ditolak dan Ha diterima. Hal ini berarti bahwa ada hubungan antara obesitas dengan arthritis reumatoid pada lansia di panti Sosial Tresna Werdha Inakaka Ambon. Penelitian ini sejalan dengan penelitian yang 
dilakukan oleh Jazmi (2016) yang meneliti tentang faktor-faktor resiko terjadinya rematik artritis pada lansia diposyandu dengan nilai $p=0,005(p<0,05)$. Hal ini di sebabkan karena responden dengan obesitas tidak mampu untuk memelihara berat badan idealnya. Selain itu, dipicu oleh ketidakseimbangan antara kalori yang masuk dari makanan dengan jumlah kalori yang keluar melalui aktivitas fisik atau olahraga. Semua lansia dengan obesitas dipanti sosial tresna werdha inakaka ambon mengeluh mengalami nyeri sendi. Hal ini mendukung teori yang dikemukakan oleh Supariasa (2012) sebagian besar lansia dengan obesitas selalu mengalami rematik. Hal ini diakibatkan karena keadaan obesitas dapat meningkatkan tekanan pada tulang sehingga tulang rawan yang terdapat di persendian-persendian yang menopang berat badan seperti sendi lutut, sendi panggul atau sendi tulang belakang bisa makin cepat aus.

Lansia dengan obesitas merupakan penyebab yang mengawali arthritis reumatoid, bukan sebaliknya bahwa obesitas disebabkan immobilitas akibat rasa sakit karena arthritis reumatoid. Pembebanan lutut, sendi dan panggul dapat menyebabkan kerusakan kartilago. hal ini juga sejalan dengan teori oleh Putra (2009) bahwa Obesitas atau kegemukan adalah istilah yang digunakan untuk menunjukan adanya penumpukan lemak tubuh yang melebihi batas normal. Penumpukan lemak tubuh yang berlebihan itu sering dapat terlihat dengan mudah. Tingkat obesitas ditentukan oleh jumlah kelebihan lemak dalam tubuh.

\section{PENUTUP}

Berdasarkan hasil penelitian maka dapat disimpulkan bahwa Ada hubungan asupan makanan dengan Arthritis Reumatoid pada lansia di Panti Sosial Tresna Werdha Inakaka Ambon., dengan hasil uji yang di dapatkan nilai $\mathrm{p}=0,000(\mathrm{p}<0,05)$. Selanjutnya juga diketahui bahwa ada hubungan antara obesitas dengan Arthritis Reumatoid pada lansia di Panti Sosial Tresna Werdha Inakaka Ambon, dengan hasil uji yang di dapatkan nilai $p=0,003(p<0,05)$

Disarankan kepada lansia yang berada di Panti Sosial Tresna Werdha Inakaka Ambon untuk menjaga berat badan agar dalam batas normal sesuai indeks masa tubuh dengan berolahraga secara teratur, kurangi mengkonsumsi jenis makanan yang mengandung purin seperti sayuran-sayuran (kangkung,daun kasbi, sawi dan lain-lain) kacang-kacangan serta jeroan. Ikuti program diet yang telah ditetapkan oleh panti sosial sesuai dengan kebutuhan masing-masing lansia. Kepada pihak Panti Sosial Tresna Werdha Inakaka Ambon, diharapkan dapat meningkatkan mutu pelayanan untuk meningkatkan kualitas hidup dan kesehatan lansia dipanti sosial tresna werdha inakaka Ambon. dengan memantau berat badan lansia agar tetap dalam batas normal sesuai indeks masa tubuh. agar terus mengontrol lansia dalam mengikuti kegiatan olahraga seperti senam, jalan pagi dan olahraga ringan secara teratur. Mengatur pola diet makanan yang dikonsumsi lansia dengan menghindari bahan makanan mengandung purin.

\section{DAFTAR PUSTAKA}

Ahdaniar, A., Hasanudin,. Indar. H, 2014. Faktor Yang Berhubungan Dengan Kejadian Penyakit Rematik Pada Lansia Di Wilayah Puskesmas Kassi-Kassi Kota Makasar. Jurnal Ilmiah Kesehatan Diagnosa, Volume 4, Nomor 2, Tahun 2014. Online diakses pada tanggal: 15 Mei 2017

Aru W. S, 2007. Buku Ajar Ilmu Penyakit Dalam edisi 4. Jakarta: Fakultas Kedokteran Universitas Indonesia.

Bandiyah. S, 2009. Lanjut Usia dan Keperawatan Gerontik. Yogyakarta: Muha medika.

Bawarodi. F, Rottie. J \& Malara. R, 2017. Faktor-faktor yang berhubungan dengan kekambuhan penyakit rematik di Wilayah Puskesmas Beo Kabupaten Talaud .e-journal Keperawatan (eKp) Volume 5 Nomor 1, Mei 2017.0nline. https://media.neliti.com/media/publications/ 114397-ID. diakses: 20 Mei 2017

DepKes. (2013). Pusat Data dan Informasi Profil Kesehatan Indonesia. Jakarta: Departemen Kesehatan RI

Jazmi, M. S (2016). Faktor Resiko Terjadinya Rematik Artritis Pada Lansia Diposiandu Wilayah Kerja Puskesmas II Baturaden. Online. diakses pada tanggal: 18 Mei 2017

Junaidi, 2012. Reumatik dan Asam Urat. Jakarta . BIP. 
Nugroho.C, 2014. Hubungan Pengetahuan Lansia tentang Arthritis Reumatoid dengan upaya Penatalaksanaannya. Jurnal AKP Vol. 5 No. 2, 1 Juli - 31 Desember 2014, Online: ejournal.akperpamenang.ac.id/index.php/akp/article/download/96/80. Diakses: 20 Mei 2017

Smith, 2006. Penyakit Radang Sendi, Jakarta. Penerbit : Rineke Cipta.

Supariasa. 2012. Gizi Pada Lanjut Usia. Jakarta FKUI.

Susanto, A. (2013). Jumlah lansia Indoneisa Lima Besar terbanyak di Dunia. Online. (http://health.liputan6.com/read/541940/jumlah-lansia-indonesia-lima-besar-terbanyakdi-dunia. diakses pada tanggal 10 Mei 2017.

Stockslager. J. L, 2007. Buku Saku Asuhan Keperawatan Geriatrik edisi 2. Jakarta: EGC.

Syam. S, 2012. Faktor-faktor yang berhubungan dengan kejadian Rematik pada Lansia di Wilayah Kerja Puskesmas Mandiangin Tahun 2012. Jurnal Kesehatan Masyarakat STIKes Prima Nusantara Bukittinggi Vol.3 $\quad$ No.2 Juli 2012.online:http://ejurnal.stikesprimanusantara.ac.id/index.php/IKPN/article/viewFile/163 L128. Diakses: 10 September 2017.

Tamsuri. A, 2008. Riset keperawatan. Kediri: Pamenang press.

Putra, Agus Antara Iwayan. 2009. Faktor Faktor Yang Berhubungan Dengan Penyakit Rematik Pada Lansia Di RW06 Kelurahan Krukut Kec. Lima Depok. Online Http://Www.Library.Upnvj.Ac.Id/Index.Php . diakses pada tanggal: 15 Mei 2017 